\title{
Planning low volume forest road-net for sustainable development in a coastline area in Chalkidiki
}

\author{
A. Stergiadou ${ }^{1}$, S. Theodoridou ${ }^{2}$, G. Zachou $^{3} \&$ A. Karagiannidis ${ }^{4}$ \\ ${ }^{1}$ Institute of Mechanical Science and Topography, \\ Faculty of Forestry and Natural Environment, \\ Aristotle University of Thessaloniki (AUTh.), Greece \\ ${ }^{2}$ Biology School, AUTh, Forester and Environmentalist, Greece \\ ${ }^{3}$ Forester and Environmentalist, AUTh, Greece \\ ${ }^{4}$ Forest Services of Drama Prefecture, AUTh, Greece
}

\begin{abstract}
Mountains have been an important part of environmental sciences. Understanding and effectively addressing the complex challenges; faced by mountain population in an era of global change requires carefully designed and implemented research involving scientists from a range of disciplines. To address the mountain problems associated with inaccessibility, fragility, and marginality; we can suggest a number of measures such as: improvement of road net; sustainability of natural resources and regulation of their usage. Furthermore, we can adopt consumption activities in order to fulfil the environmental and decentralized needs of the residents in order to develop ecotourism to a semi mountainous area. The aim of this paper is: a) to record the current situation of Cassandra's road net in a semi mountainous area, b) to propose places that can be further developed and; c) to develop an estimating method of parametric system based on environmental impact assessment. The results of our research are based on; how until now this area has been managed and how we are going to reform it by our proposals; by the usage of road net and the rural development. We used a route; which passes through several forest stands and is preferred compared to the provincial highway which is used as a connecting axis between the cities of Cassandra and Fourka. Another ultimate aim is to propose structures that could improve these sections of forest land to
\end{abstract}


upgrade the area; to increase the percentage of forest road crossing and the multiple-use by hikers and visitors. As a goal is the visit ability of this semimountainous area by pupils with low incomes or by more affluent groups. Finishing this task, we believe it contributed even slightly to the sustainable development of the area of Cassandra; while such projects should be provided and assistance is granted by the Prefecture and local governments to expand the horizons of development of non-urbanized areas.

Keywords: planning, low volume forest road-net, sustainable development, semi mountainous area, environmental impact, Cassandra, Greece.

\section{Introduction}

Forested areas are almost 65.130 .000 ha $\cong 49.5 \%$ of Greece and that makes them important for the environmental sciences [1]. We address the mountain specified problems associated with inaccessibility, fragility, and marginality, so that we can suggest a number of measures such as: improvement of road net; sustainability of natural resources and regulation of their usage. Furthermore we can adopt interactive activities in order to fulfil the environmental and decentralized needs of the residents. That can develop eco-tourism to a semi mountainous area.

Sustainable management is in harmony with environmental protection from both quantitative and qualitative terms, since the objective is to use the resources of the planet to the point of tolerance [2]. The concept of sustainable development as determined through an exhibition Brutland is not limited to the sustainable use of natural resources and natural systems, but extends to political and economic factors, and also recognizes the need for global action with the cooperation of all countries [3]. Sustainable development is closely linked to the sustainable management of natural resources of the planet, but also with care to satisfy the developmental and environmental needs of future generations [4]. Sustainable development means that it preserves the overall quality of life, sustainable use of natural resources through a process where the flow for materials in various stages of processing consumption and use should facilitate or encourage optimum reuse and recycling [5].

Overcrowding combined with unpleasant environmental conditions and lack of adequate quantity and quality, green outbreaks in urban centres led the people to seek leisure near nature in suburban forests, forming a forestry recreation. By default, forest recreations are all forms of outdoor recreation that takes place in forest areas; where the forest has a preponderant role in recreational activities. Many factors affect the demand for forest recreation such as the population size, place of residence, living zone, occupation, economic factor, transportation factor, time, etc. Satisfying the demand for recreation requires the availability of an area; and the pupils' interest for those places. The factors which are affecting the value of the proposed sites and their suitability for development of forest recreation; can be classified into three categories factors: a) natural, b) biotic and c) cultural. 


\section{Research area}

The low volume forest road is located in the prefecture of Chalki-iki, in the Municipality of Cassandra. This road starts from Cassandra village $\left(23^{\circ} 24^{\prime} 50.98^{\prime \prime}\right.$ east of Greenwich and $40^{\circ} 2^{\prime} 23.81^{\prime \prime}$ north of the Equator), and ends just before the entrance to the village of Fourka $\left(23^{\circ} 25^{\prime} 15.92^{\prime \prime}\right.$ east of Greenwich and $40^{\circ} 0^{\prime} 37.79^{\prime \prime}$ north of the Equator) (Map 1).

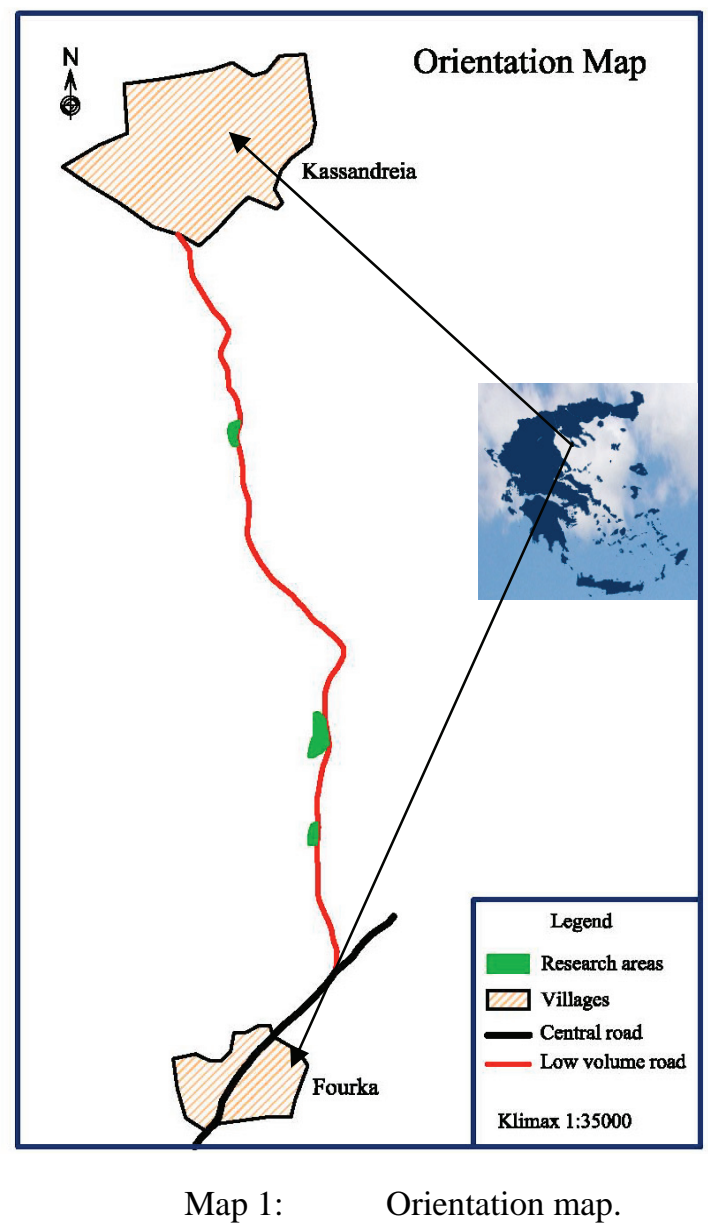

The reference to the conditions of the road accessibility, are considered good as it is accessible from both Fourka's and Cassandra's villages, while leading rural roads as a low volume street of the central axis.

The average gradient along the route of the road ranges from $35 \%$ to $50 \%$. The soil is sandy and deep and there are a small number of irrigation wells. The soils in Cassandra are sand-clay and clay, angular with strong granular structure. It is typical for these territories to have a high ph and magnetite. Particular 
clusters are characterized by sedimentary loam, silt-sand sedimentary rocks and sometimes alluvial sediments. The climate of Cassandra in coastal areas is temperate but also in inland areas, it's not rough.

The vegetation of the area is rich with the dominant forest species: Pinus halepensis, Fagus silvatica and Picea abies. Other species scattered or in small groups and sessions mixed forest species in the ecosystem, are broadleaves, Pistacia lentiscus, Arbutus unedo, Myrtus communis, Arbutus andrachne and Erica arborea. Moreover, outweigh the understudy, the Quercus ilex and Fraxinus ornus, found in northern and north-western cluster of reports, which are aside the low volume road net. The forest type which constitutes the area is mainly the same aged cluster, semi-planted and trees of different ages. The largest number of trees commonly found in the lower age class. The ecological setting of the area is quite good to moderate.

The Mediterranean climate of coastal regions where there are extensive olive groves is characterized by mild winters and cool summers. The microclimate in lowland areas contributes to the absence of frosts or excessively high temperatures. The coldest months are February and March but without creating problems where the average minimum temperatures are above $0^{\circ} \mathrm{C}$. The average annual rainfall ranges from $500-600 \mathrm{~cm}$. The majority of rain falls during the period from October until April. The winds that blow in the area are mainly from north-northeast while south winds blow mainly during the summer.

\section{Methods}

The equipment which we have used and helped us to the termination of our research includes: topographical map with the forest types in the research area, describing sheets clusters along the way, literature data related to forest recreation and improvement of forest roads, rangefinder (TruPulse 360/360B), photographs of the area and constructions. We used the program AutoCAD for the accurate mapping and design, both engineering structures in the region.

The first stage was the data selection in the studied area. We visited the area and walked along the low volume road net so as to identify the positions, where the proposed construction projects of recreation can be built. The principles which have been taken in order to choose recreation areas are: guest satisfaction, management and access to forest and the ratio of natural resource to visitor. We selected the locations by taking into account some basic principles and specific factors affecting the site. These elements can be applied to each site selected for forest recreation.

This was followed by recording and processing the data, of the positions which were selected for further development using the rangefinder (TruPulse 360/360B). The laser range sensor determines distance by measuring the time it takes for each pulse to travel from the rangefinder to the target, and back. In each selected area measured on the coordinates and the perimeter in order to provide the best accuracy and acquisition distance (Table 1, Map 2).

In the next step, projects for improvement were proposed for the selected places, such as recreational structures (kiosks, view positions, etc.) and suggestions for improvement of the route along the road (with technical works 
Table 1: $\quad$ Coordination measurement with TruPulse 360.

\begin{tabular}{|c|c|c|}
\hline $\mathrm{A} / \mathrm{A}$ & $\mathrm{x}$ & $\mathrm{Y}$ \\
\hline 0 & 449592,79 & 4432456,90 \\
\hline 1 & 449711,85 & 4432112,94 \\
\hline 2 & 449910,29 & 4431782,21 \\
\hline 3 & 450002,89 & 4431332,42 \\
\hline 4 & 449976,43 & 4431028,15 \\
\hline 5 & 449989,66 & 4430869,40 \\
\hline 6 & 450241,02 & 4430657,73 \\
\hline 7 & 450492,37 & 4430366,69 \\
\hline 8 & 450479,14 & 4430300,54 \\
\hline 9 & 450413,00 & 4430247,63 \\
\hline 10 & 450386,54 & 4430088,88 \\
\hline 11 & 450399,77 & 4429784,61 \\
\hline 12 & 450320,39 & 4429533,25 \\
\hline 13 & 450452,68 & 4429255,44 \\
\hline 14 & 450479,14 & 4429162,83 \\
\hline 15 & 450558,52 & 4429017,31 \\
\hline $\mathrm{A} / \mathrm{A}$ & $\mathrm{x}$ & $Y$ \\
\hline 64 & 449989,66 & 4431213,36 \\
\hline 65 & 449963,20 & 4431372,11 \\
\hline 66 & 449870,60 & 4431451,48 \\
\hline 67 & 449923,52 & 4431544,09 \\
\hline 68 & 449963,20 & 4431583,78 \\
\hline 69 & 449936,75 & 4431689,61 \\
\hline 70 & 449936,75 & 4431689,61 \\
\hline
\end{tabular}

\begin{tabular}{||c|c|c||}
\hline$A / A$ & $X$ & $Y$ \\
\hline 16 & 450558,52 & 4428951,17 \\
\hline 17 & 450571,75 & 4428832,10 \\
\hline 18 & 450479,14 & 4428686,58 \\
\hline 19 & 450360,08 & 4428567,52 \\
\hline 20 & 450307,16 & 4428488,14 \\
\hline 21 & 450201,33 & 4428435,23 \\
\hline 22 & 450121,95 & 4428329,39 \\
\hline 23 & 450161,64 & 4428461,69 \\
\hline 24 & 450267,47 & 4428527,83 \\
\hline 25 & 450439,45 & 4428673,35 \\
\hline 26 & 450518,83 & 4428818,87 \\
\hline 27 & 450505,60 & 4428911,48 \\
\hline 28 & 450505,60 & 4428937,94 \\
\hline 29 & 450532,06 & 4428977,62 \\
\hline \hline 30 & 450413,00 & 4429228,98 \\
\hline 31 & 450333,62 & 4428990,85 \\
\hline
\end{tabular}

\begin{tabular}{|c|c|c|c|c|c|}
\hline A] & $x$ & Y & /A & $\mathrm{x}$ & Y \\
\hline 2 & 70 & & 48 & & \\
\hline 5 & & & 49 & 70 & 42 \\
\hline 34 & 50241,02 & [E & 50 & 45028 & 429 \\
\hline 35 & 5028 & 4429 & 51 & 7,16 & 4429956,59 \\
\hline 6 & 93 & & 52 & 62 & 42 \\
\hline 37 & 50373,31 & E & 53 & 3,93 & 4436 \\
\hline 38 & 50346,85 & 4429 & 54 & 450333,62 & 4430075,65 \\
\hline 9 & 0280 & & & 3,00 & 430 \\
\hline 40 & 450320,39 & 442 & 56 & 6,23 & 4430234,40 \\
\hline 41 & 450346,85 & +29 & 57 & 4504 & 443030 \\
\hline 42 & 450360,08 & 4429 & 58 & 45047 & 4430327,00 \\
\hline 43 & 450360,08 & 428 & 59 & 45039 & 4430419,6 \\
\hline 44 & 450386,54 & 4429 & 60 & 450280,70 & 4430591,59 \\
\hline 45 & 450360,08 & 4429797,8 & 61 & 450214,56 & 4430657,7 \\
\hline 46 & 450360,08 & & 62 & 450042,58 & 430737,11 \\
\hline 47 & 450346,85 & 4429877,21 & 63 & 450002,89 & 4430869,4 \\
\hline
\end{tabular}

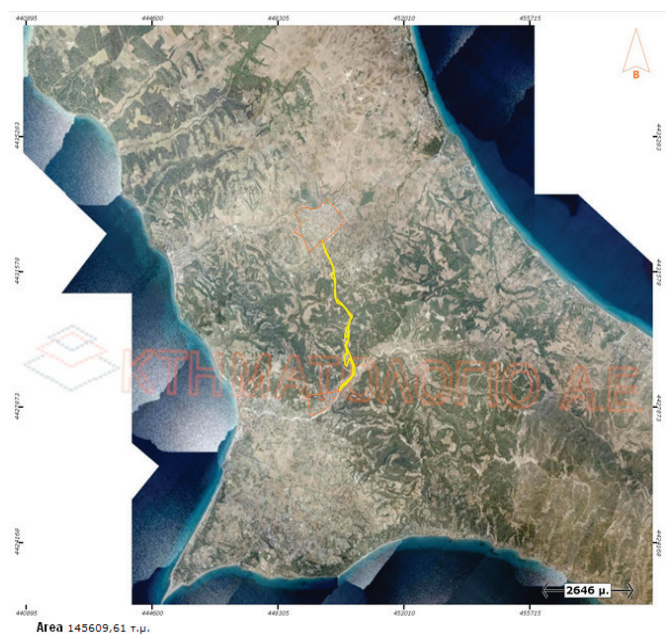

Map 2: $\quad$ Topographical diagram based on the Greek surveying system. (Source: www.ktimanet.gr.)

such as better road pavement, traffic signs, etc). We made an exact selection of proposed projects in these places along the way of low volume road, after careful review and assessment of the current situation in the region.

The region which we examined is characterized by a clear change of the local population in the past few years (1998-2002). The town of Cassandria has 3,500 inhabitants and in the summer with the summer settlements is a big city of 25,000 inhabitants. The population of the region in 1998 amounted to 7,415 
inhabitants, while in 2002 increased to 10,269 inhabitants [6]. In particular, the forest road Cassandra-Fourka, after the research we conducted showed that it's most frequently used by residents of these areas, in comparison with the main road.

In the research area we noticed that there are several places that could be used to enhance sustainable development in the region. These are mainly from the right side (heading towards Fourka) of the road where there are uncovered areas surrounded by lush vegetation that makes these areas ideal for further development. So, at such locations we suggest a number of technical projects that will enhance their respective landscapes while attracting more people to visit them for activities.

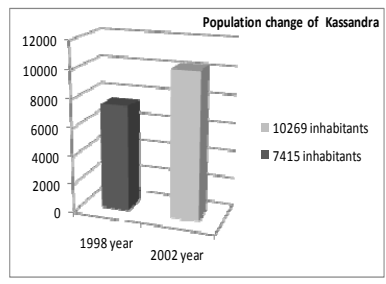

Figure 1: Hellenic statistical authority [6].

Practical criteria have been held in order to evaluate the absorption of the impact. The grading of these criteria depends on the following principle: We accept a situation as ideal $(=100 \%)$ for the forest protection from construction. This ideal situation will be described by criteria. The following parameters have been considered: a) the duration of the negative effect, b) the influenced area, c) the sensitivity of the general public to the effect as well as the social impact and political desire. The evaluation of the latter parameters will be difficult and therefore the description of an EIA in a profile form will be a necessary addition [7-10]. The identification and the rating of criteria for assessing environmental impacts of the proposed constructions through impact absorption will allow for comprehensive evaluations of every construction according standards set by EU directions. The equation for compatibility of the proposed constructions and the natural environment of these biotopes is: $\mathbf{C}=\mathbf{M A ~ X ~ M E}$, where: $\mathrm{C}(\%)=$ Compatibility, MA (\%) = Mean Absorption, ME (\%) = Mean Intensity [11, 12].

\section{Planning and study results}

\subsection{Criteria of absorption}

The capacity of optical absorption of landscape shows the possibility of landscape to "acquiring" procedures such as human constructions or intense management interventions. This feature depends on topography, the forest species, the change of vegetation, etc. The gradation of absorption criteria are based on: the kind of terrain conditions and the distance between the selected sites for the constructions and other interesting locations. The values of Weights are: $\mathbf{1}=\mathbf{m i n}$ (not important), $\mathbf{2}=\mathbf{m e d}$ (important) and $\mathbf{3}=\mathbf{m a x}$ (very important). It 
is also well known that the absorption can be measured by: the type of Forestall plants (pinus, acer, etc), the topography of the location and so on. In Table 2 we measured the terrain conditions for the road constructions and for the nature and the distance of our research areas from important places (villages, bus station, etc), in order to calculate the average clause by deviate the sum of each selected area with the weights of our criteria.

Table 2: $\quad$ Criteria of absorption at the selected areas.

\begin{tabular}{|c|c|c|c|c|c|c|c|}
\hline \multicolumn{8}{|c|}{ Criteria of absorption } \\
\hline \multirow{2}{*}{ 1. Terrain conditions } & \multirow{2}{*}{ Weights } & \multicolumn{2}{|c|}{ Selected Area 1} & \multicolumn{2}{|c|}{ Selected Area 2} & \multicolumn{2}{|c|}{ Selected Area 3} \\
\hline & & GRADE \% & SUM & GRADE \% & SUM & GRADE \% & SUM \\
\hline 1.1 Forest & 3 & 100 & 300 & 100 & 300 & 100 & 300 \\
\hline 1.2 Mixed forest & 3 & 70 & 210 & 70 & 210 & 65 & 195 \\
\hline 1.3 High forest & 3 & 60 & 180 & 100 & 300 & 70 & 210 \\
\hline 1.4 Selection forest & 3 & 50 & 150 & 50 & 150 & 50 & 150 \\
\hline 1.5 Mean height & 3 & 80 & 240 & 90 & 270 & 80 & 240 \\
\hline 1.6 Side quality & 3 & 50 & 150 & 50 & 150 & 50 & 150 \\
\hline 1.7 Productivity & 3 & - & - & - & - & - & - \\
\hline 1.8 Slope & 2 & 25 & 50 & 25 & 50 & 25 & 50 \\
\hline 1.9 Relief & 2 & 100 & 200 & 100 & 200 & 90 & 180 \\
\hline \multicolumn{8}{|l|}{ 2. Distance from } \\
\hline 2.1 Tourist places & 2 & 100 & 200 & 100 & 200 & 100 & 200 \\
\hline 2.2 Highway & 1 & 80 & 80 & 75 & 75 & 80 & 80 \\
\hline 2.3 Railway & - & - & - & - & - & - & - \\
\hline 2.4 Archaeological sites & & - & - & - & - & - & - \\
\hline 2.5 Town & 1 & 90 & 90 & 90 & 90 & 100 & 100 \\
\hline 2.6 Village & 1 & 100 & 100 & 100 & 100 & 100 & 100 \\
\hline 2.7 Path way & 1 & 100 & 100 & 100 & 100 & 100 & 100 \\
\hline Sum & 31 & & 2050 & & 2195 & & 2055 \\
\hline \multicolumn{3}{|c|}{ Average clause (\%): weight/sum } & 66,12 & & 70,806 & & 66,29 \\
\hline
\end{tabular}

\subsection{Environmental study on wooden and concreted constructions}

It is recommended to use timber as a material of construction works, because it is a natural product. Especially in a forest, technical construction uses "composite wood" because it is $40 \%$ stronger than the rigid timber has $360 \mathrm{kp} / \mathrm{m}^{2}$ strength and weight nearly $480 \mathrm{~kg} / \mathrm{m}^{3}$. The ratio weight and strength of wood is better than conventional construction materials (Table 3) [13].

Wood is the best environmental option as it is a natural and recyclable material. In each country which is encouraged to support sustainable development, the only material available that meets the above criterion for the construction projects is wood.

\subsection{Recommended projects and technical features}

In all the selected locations it is proposed to establish wooden garbage bins (B) as well as fire safety signs (FS). The observance of cleanliness for recreational 
Table 3: $\quad$ Ratio of weight and durability of wood.

\begin{tabular}{|l|c|c|c|}
\hline \multicolumn{1}{|c|}{ Material } & Strength (bending) $\mathbf{~ k g / \mathbf { c m } ^ { 2 }}$ & Density $\mathbf{~ k g} / \mathbf{m}^{\mathbf{3}}$ & Ratio of resistance \\
\hline Glulam & 140 & 490 & 0.285 \\
\hline Structural steel St37 & 1400 & 7800 & 0.179 \\
\hline Full timber & 85 & 550 & 0.155 \\
\hline C12 concrete & 80 & 1800 & 0.045 \\
\hline
\end{tabular}

areas with the collection and disposal of waste is a serious problem [14], especially in our country where environmental awareness in the community hasn't developed. What should first be sought is the discharge of waste with well-established positions. So, it is necessary to place wooden garbage bins (1-2), because anyone can combine a walk with a rest for an outdoor lunch (picnic). The wooden garbage bins can be used to prevent the pollution created by the scattering of rubbish in the areas. Moreover, it is necessary to put up signs of fire hazard warning. Because of the increased risk of fire especially during summer months, forest areas are required to place signs to prevent and suppress such disasters. This increases the responsibility of the visitor towards the environment.

Furthermore, besides these, in every region, recommended sustainability plans are proposed depending on the capabilities and needs of each of these in the context of forest recreation. At the same time we propose technical works associated with each area:

\subsubsection{First area}

This first place is indicated as an area of recreational exercise, since it is located within a short distance from Cassandra, which is accessible by walking. It could be seen as a nearby recreation area due to its proximity to the permanent residence of the locals and the short time required visiting the place. Combined with the above is that the road permeates the area has good flow.

The projects proposed for this area are (Design 1):

a) Football field 5x5: in the first place soccer $5 \times 5$ serving young people since it offers them sport and exercise, stimulating and fun for exercisers and audience, increases social behaviour, gives the opportunity for training camps within the physical education lessons. The area where this stadium is proposed is sufficiently large for such technical project while being easily accessible. We recommend a small football field with a plastic surface such as turf, which has prevailed for several reasons. The main reason is the difficulty to maintain although of the natural grass due to the climate, but it does not offer the same flexibility to absorb vibration of the body as the turf one.

b) Kiosk: near the location of the stadium a wooden pavilion can be made, that will serve some rest to the visitors. The wooden pavilion that offers: rest and relaxation, protection from sudden weather conditions (rain, storm, etc.), offers shade from the sun and it can be a place for a snack or picnic. The proposed material for that forestalls construction is wood. The wood is environmentally friendly and more suited to forest landscapes. 
c) Faucet (F): the area where we propose to construct the soccer field and the kiosk will not constitute a comprehensive recreation site without a faucet. Since in the area there is a natural source, it is easy to provide water to the tap from this source. It is proposed to be stone built in order to blend aesthetically with the surroundings (2).

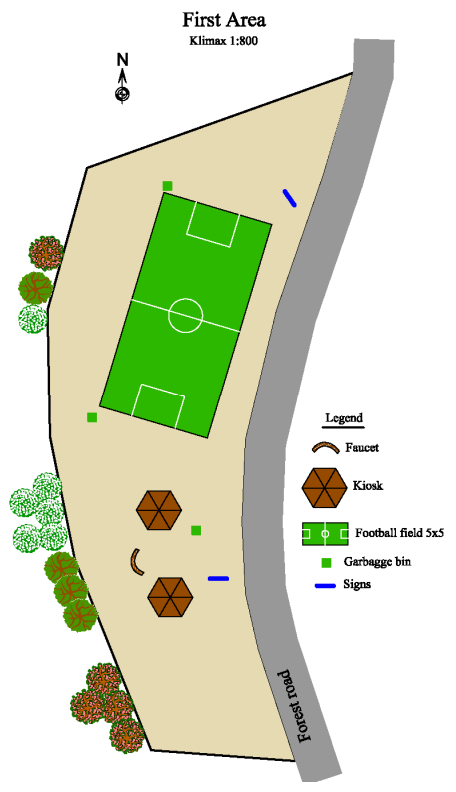

Design 1: $\quad$ First area.

\subsubsection{Second area}

The second section is $2.3 \mathrm{~km}$ from Kassandreia near the church of St Marina, where a festival takes place from 19 to 20 July. The recommended construction (Design 2) is:

a) Configuring the region for the festival: with folding fabric awnings.

b) Compost bins: in compost bins, organic waste (fruits, vegetables, leaves, etc.) are converted into a rich organic mix, which acts as soil conditioner and fertilizer. By composting we can reduce all of our household waste by $35 \%$ and reduce the trash going into landfills. This has multiple benefits: (a) reduce overall quantities of waste; (b) significantly prolong the life of the landfill after receiving less waste; (c) protect the planet from global warming; (d) and another problem that solves the composting organic waste is desertification of soils. The compost, which is the product of composting, returns to the soil, necessary for the soil's fertility, organic and inorganic substances. In addition to compost bins, it would be useful to place recycling bins for other inorganic materials (paper, plastic, glass, cans, etc).

c) Parking with natural shading from trees: the space is sufficient for about 30 40 cars and buses. It would be also useful to place near the street, a wooden sign for parking. 


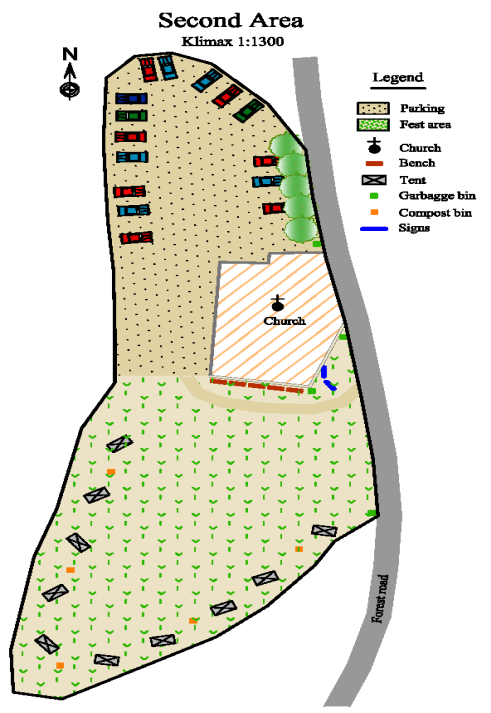

Design 2: $\quad$ Second area.

\subsubsection{Third area}

The third place is at the end of the route and may be a small recreation area. At this point a faucet and water troughs already exist, so there could be placed some structures (Design 3):

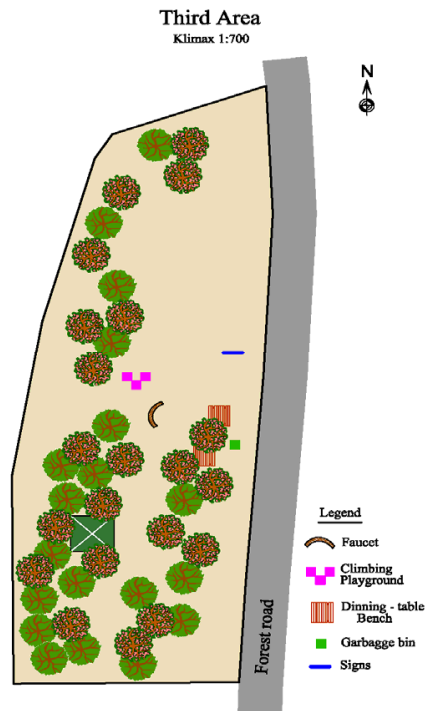

Design 3: $\quad$ Third area. 


\subsection{Along the road the following constructions are proposed}

1. Informative signs, Kalambaka type (type A): It is proposed to place (6) notices of type $\mathrm{A}$ at a distance of $20 \mathrm{~m}$ before the following points: in the $5 \mathrm{x} 5$ football field, at the Church of St. Marina, in the third region (interactive site). An information sign will include the elements of the service and the names of the respective points.

2. Directional information signs: it is proposed to place two (2) notices of direction, type A, which are signs of general information. The summary of proposed projects is shown in Table 4.

Table 4: $\quad$ Summary of proposed project.

\begin{tabular}{|c|c|c|c|c|c|c|c|c|c|c|}
\hline \multirow[b]{2}{*}{ 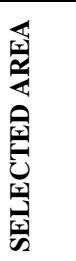 } & \multicolumn{10}{|c|}{ CONFIGURATION OF SCOPE } \\
\hline & 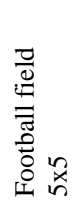 & $\begin{array}{l}\frac{y}{y} \\
\ddot{0}\end{array}$ & 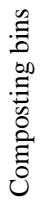 & 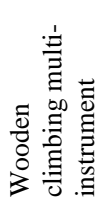 & 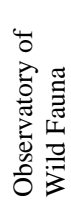 & 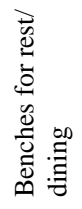 & 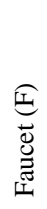 & 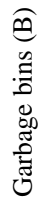 & 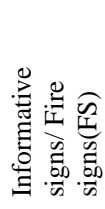 & 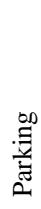 \\
\hline $1 \mathrm{st}$ & $\checkmark$ & $\checkmark$ & & & & $\checkmark$ & $\checkmark$ & $\checkmark$ & $\checkmark$ & $\sqrt{2}$ \\
\hline 2nd & & $\checkmark$ & $\checkmark$ & & & $\checkmark$ & & $\checkmark$ & $\checkmark$ & $\sqrt{2}$ \\
\hline 3rd & & & & $\checkmark$ & $\checkmark$ & $\checkmark$ & $\checkmark$ & $\checkmark$ & $\checkmark$ & \\
\hline
\end{tabular}

\section{Conclusions and proposals}

With the staging of our work, we separated it in the three main pieces: a) Field Work (select one area of forest road, walking on the forest road, identifying potential points for improvement, etc.) b) recording and processing of selected data points c) designing of the proposed projects and d) presentation of final proposals to study the sustainable development of the region.

The average values for the optical absorption capacity of each selected areas for regeneration, are about the same (66.12\%, 70.806\% and 66.29\%) and over $50 \%$ is necessary because that makes acceptable our proposed development. In the second selected area (S.A.2) the percentage is higher (71\%) because the site is already formed to some extent; since there is the church of Saint Marina where during the summer there is a festival. So there the terrain slope is nearly $5 \%$ and the accessibility conditions are very good.

Our proposals refer to the improvement of certain parts at the right side of the road, with forest recreation structures based on the principles of sustainable use. We believe that this structural plan can be accepted for funded from the Prefecture because it has low cost and was designed based on the sustainable rural development criteria. That can give employment of local population and the growth of tourism at a pace commensurate with the physical development and not with the speed desired by the short-term economic forecasts. 


\section{References}

[1] Minagric 2012, The value of the forest. www.minagric.gr/greek/ agro_pol/dasika/forests/forests1.htm

[2] Stergiadou A., 2007. Sustainable development of coastal forested areas by using an environmental opening up strategy, CEMEPE Proc. of SECOTOX Conference on Environmental Management Engineering, Planning and Economics, v.1, pp. 739-744, Thessaloniki.

[3] United Nations. 1987. Report of the World Commission on Environment and Development, General Assembly Resolution 42/187, 11 December 1987. Retrieved: 2007-11-14.

[4] WCED (World Commission on Environment and Development), 1987. Our Common Future. Oxford, UK: Oxford University Press.

[5] Stergiadou A., 2001. Promotion, sustainable development and forest open up of the mountain region (regions: Grevena, Ioannina and Kilkis), Doctoral Thesis in Geotechnical School, A.U.Th., Greece. http://phdtheses. ekt.gr/eadd/handle/10442/22812.

[6] Hellenic statistical authority, 2012. Human population, www.statistics.gr

[7] Eskioglou P. and Efthymiou P., 1995. Alternative stabilization methods of forest roads for an efficient and gentle mechanization of wood harvesting systems, http://www.fao.org/documents/en/docrep.jsp (6.05.2012).

[8] Koutsopoulos N. and Yang Q., 1992. Modelling requirements for emerging transportation system operating environments. Report DTRS-57-88-C0078, TTD 29, John A. Volpe National Transportation Systems Center, Cambridge, MA.

[9] Koroneos C., Bouras A., Mousiopoulos N., Balla C. 1999. Life Cycle Analysis: A Comprehensive Approach. Proceedings of Heleco 1999: "Environmental Technology for the 21st Century", Vol. II, Third International Exhibition and Conference (3-6 June 1999, Thessaloniki), TEE, Athens.

[10] Doucas K., 2004. Forest Construction, Giachoudis press, pp. 346, Thessaloniki, Greece.

[11] Stergiadou A., 2006. Environmental impact assessment (E.I.A.) for the evaluation of forest roads in mountainous conditions (case study: Valia Kalda), Proceedings of International Conference "Sustainable Management and Development of Mountainous and Island Areas", $29^{\text {th }}$ Sep. $-1^{\text {st }}$ Oct. 2006, Island Naxos, Greece, Pub: D.U.Th., pp. 125-129, Orestiada.

[12] Stergiadou A., 2007. Sustainable development of "Smixi" using environmental impact assessment, Sustainable Development and Planning III, Vol. 2, pp. 281-291, WIT press Transaction on Ecology and the Environment, Vol. 102, ISSN:1743-3541 (on-line).

[13] Democritus University of Thrace (DUTh.), 2012. http://diocles.civil.duth.gr/ links/home/museum/mater/wood/wood7.html

[14] Liakos L., 1977. The recreation in forests. Aristotle University Press, pp. 365, Thessaloniki, Greece.

[15] Papageorgiou N.K., Game Breeding, University Studio Press, Thessaloniki, 1996. 